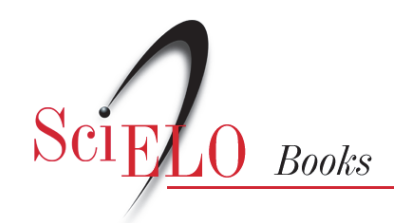

\author{
A casa é o habitat humano \\ Maria de Fátima de Araújo Silveira \\ Hudson Pires de Oliveira Santos Junior \\ Jaqueline Queiroz de Macedo
}

SILVEIRA, MFA., and SANTOS JUNIOR, HPOS., orgs. Residências terapêuticas: pesquisa e prática nos processos de desinstitucionalização [online]. Campina Grande: EDUEPB, 2011. 320 p. ISBN 97885-7879-063-9. Available from SciELO Books $<\underline{\text { http://books.scielo.org }>\text {. }}$

\title{
(1)(1)(2)
}

All the contents of this work, except where otherwise noted, is licensed under a Creative Commons Attribution-Non Commercial-ShareAlike 3.0 Unported.

Todo o conteúdo deste trabalho, exceto quando houver ressalva, é publicado sob a licença Creative Commons Atribuição Uso Não Comercial - Partilha nos Mesmos Termos 3.0 Não adaptada.

Todo el contenido de esta obra, excepto donde se indique lo contrario, está bajo licencia de la licencia Creative Commons Reconocimento-NoComercial-CompartirIgual 3.0 Unported. 


\section{A Casa é o habitat humano}

Maria de Fátima de Araújo Silveira Hudson Pires de Oliveira Santos Junior Jaqueline Queiroz de Macedo

Começamos com uma indagação: qual é esse lugar que nós chamamos de lar?

Para Antônio Averlino, arquiteto italiano do medievo, mais conhecido como Filarete (RYKWERT, 2003), foi a partir da expulsão do paraíso que Adão, ao defrontar-se com a primeira chuva, estendeu as mãos cruzadas sobre o rosto, em um gesto de defesa, instituindo o primeiro abrigo, a primeira arquitetura.

Esse abrigo primordial - hupah - é simbólico, constituído de folhas, sendo, contemporaneamente, também, local de realização de casamentos judeus, portanto, de territorialização do casal e, posteriormente, da família. O hupah "era (é), em resumo, tanto uma representação do corpo de seus habitantes quanto um mapa, um modelo, e uma interpretação do mundo" (RYKWERT, 2003).

Com um olho no passado e outro no futuro, Joseph Rykwert, um dos mais respeitados historiadores da Arquitetura, aborda, em "A Casa de Adão no Paraíso" (RYKWERT, 2003), as referências arquetípicas do homem com o seu abrigo e, a partir daí, o lugar da arquitetura na formação cultural da sociedade humana. Em sua investigação, o autor recorre à antropologia, em um minucioso processo 
de relações entre fatores identitários e produção arquitetônica ao longo dos séculos. Para compreendê-los em seu devir temporal, o historiador recorre a múltiplas vias: o Livro Santo e outros escritos sagrados, ritos, obras de arquitetura e práticas construtivas. A observação dos ritos é um distintivo do autor, que não distingue entre os dois leitos, entrevendo continuidades, permanências de posturas, de aspirações que dissipam os limites estanques entre Razão e Mito.

Ao abordar as origens da arquitetura - ou da cabana primitiva um projeto arquitetural para o futuro e as formas de renovação de sua linguagem, Rykwert destaca que não basta o esquadrinhamento da primeira casa como aparato conceitual. É salutar, lembra o historiador, abeberar-se noutra fonte, anterior, onde se "rememorava a sua forma e natureza mediante cerimônias e ritos de povos que, todavia, uns ainda chamam de primitivos" (RYKWERT, 2003).

Ao adentrar no terreno das referências teóricas sobre a casa, inúmeras possibilidades se avizinham no horizonte, devido, entre outros motivos, ao fato de que cada civilização ou período histórico ter a sua forma particular de construção, entretanto, possuindo características comuns: como a de ser um abrigo, ter solidez para garantir resistência a agressões, ser espaço de conforto e intimidade.

O tratado mais antigo sobre a arquitetura da cidade e suas edificações é de autoria de Vitrúvio, arquiteto romano, que na Antiguidade Clássica escreveu De Architectura Libri Decem, a única obra de arquitetura do mundo antigo e a principal fonte sobre a Antiguidade Clássica, composta por dez livros. Neles, o autor apresenta Roma como a cidade ideal, modelo que utiliza para propor a cidade "Vitruviana", cuja ênfase é a disposição da trama viária. Por admirar a cidade, centro do poder imperial, Vitrúvio apresenta preocupação com as estruturas defensivas e questões de segurança, estabelecendo uma divisão na diversidade de construções e diferenciações entre os homens: 
$\mathrm{O}$ ato de construir é dividido em duas partes, sendo a primeira a construção de cidades fortificadas e de obras para o uso geral em locais públicos; e a segunda, a construção de edifícios para indivíduos privados. Os edifícios públicos são divididos em três classes: para defesa, religião e propósitos utilitários. Aqueles que se referem à defesa são o arranjo das muralhas, torres, pontes, portões e inventos permanentes para a resistência contra ataques hostis; os relativos à religião são altares e templos erguidos aos deuses imortais; e os que dizem respeito à utilidade são a provisão de locais de encontro para uso público, tais como portos, mercados, colunatas, termas e todos os outros arranjos similares em locais públicos. Vitrúvio acrescenta, então, que "tudo isto deve ser construído com devida referência à durabilidade (firmitas), conveniência (utilitas) e beleza (venustas)" (RYKWERT, 2003 ).

Esse antigo arquiteto aconselha que as construções devem ter em vista a divisão de classes que compõem a república e as colônias: "um segundo estágio em economia é alcançado quando temos que conceber os diferentes tipos de moradias adequados para os proprietários de casas comuns, para os de grande riqueza, ou para a alta posição de homem de estado". Fazendo de sua voz, o registro de ideias de sua classe, ainda assim, ressalta que é importante que haja "casas para toda e cada classe". Embora concedendo importância secundária, Vitrúvio recomenda que se pode e se deve adornar a cidade com monumentos esplêndidos, porém tendo como valor ideal o Estado romano (RYKWERT, 2003 ).

Apesar de única, durante todo o período da Idade Média, a obra de Vitrúvio foi pouco utilizada, sendo retomada, no Renascimento, devido às buscas por inovações defensivas, disparadas pela introdução da pólvora na artilharia. 
O principal arquiteto a se apropriar das ideias contidas na obra vitruviana foi o italiano Leon Battista Alberti, que publicou De Re Aedificatoria, estruturada, também, em dez livros, imprimindo uma visão renascentista de um ideal de cidade. Nesta obra, o autor propõe, e ratifica, a construção de edifícios em tipologia determinada pela estratificação social, quando afirma: “...escolher-se-ão poucos indivíduos na comunidade inteira, alguns dos quais distinguem-se por conhecimento, sabedoria, engenho, outros por experiência e prática das coisas, outros, enfim, por riqueza e abundância nos bens de fortuna" (SOUSA, 2008).

Alberti também discorre sobre os elementos de que se necessitam para formar a cidade, a saber: muralhas, fortes, ruas, pontes, esgotos e portos. Suas apreciações possuem sempre um valor prático, explicitam uma téchne para a construção da cidade. Na sua obra, pensa a configuração da cidade como reflexo da estrutura social, juntamente com uma série de considerações práticas, funcionais e higiênicas. $\mathrm{O}$ Livro X é um tratado de hidráulica, por exemplo.

Tanto Vitrúvio quanto Alberti vão descrever princípios tendo em vista um modelo de cidade ideal. "Os tratados de arquitetura concorrem em larga medida para a constituição e difusão da doutrina da cidade (...). A fonte primeira continua sendo o Tratado de Vitrúvio, que já conhecido na Idade Média, tornou-se o texto básico para os tratadistas de arquitetura (...)" (SOUSA, 2008)..

No rastro dessa obra, vão surgir os Tratados de Antonio Averlino ditto il Filarete (1460), Francesco di Giorgio Martini (1482) e Leonardo da Vinci (1485). Tal fato reforça a importância da obra geminal de Vitrúvio. 


\section{A casa não é apenas uma casa - em busca do abrigo}

Se a geografia, a arquitetura e a etnografia descrevem os mais diversos tipos de habitação, a fenomenologia procura revelar a "função original do habitar" e compreender a semente da "felicidade central, segura, imediata", descrita por Bachelard (2008), pois "todo o espaço realmente habitado traz a essência da noção de casa (...) e a casa é o nosso canto do mundo, o nosso primeiro universo".

A função primordial e simbólica da casa é abrigar e proteger, pois o homem só pode ser verdadeiramente homem quando tem um lar, uma casa.

A casa é uma das maiores forças de integração para os pensamentos, as lembranças e os sonhos do homem. Nessa integração, o princípio de ligação é o devaneio. (...) Sem ela, o homem seria um ser disperso. Ela mantém o homem através das tempestades do céu e das tempestades da vida. É corpo e é alma. É o primeiro mundo do ser humano. Antes de ser "jogado no mundo" (...) O homem é colocado no berço da casa (BACHELARD, 2008).

Para esse autor, a casa, através da sua representação simbólica, possibilita ao homem um enraizamento mais profundo na vida, constituindo-se como um elemento de estabilidade, sendo uma das maiores força de integração na vida do sujeito, pois a casa abriga o devaneio, protege o sonhador, permitindo-o sonhar em paz, pois em seu interior se encontram os "espaços felizes". Assim, "habitar não significa estar abandonado em qualquer lugar de um mundo hostil; mas significa estar abrigado graças ao amparo da casa". Ao se limitar aos "espaços felizes" (sótão, pavimento térreo e porão), a casa de Bachelard deixa de fora os "espaços de ódio e de combate (jardins, quintais, dependências, todas as áreas externas)" (Sousa, 2008). 
Para dar conta de tantas funções, Bachelard (2008) discorreu sobre a necessidade de a casa ter não apenas a dimensão horizontal, mas ser desenvolvida verticalmente, prolongando-se em altura e profundidade. A sua casa onírica, portanto, deve conter três andares: o pavimento térreo, o sótão e o porão, símbolo do alto e do baixo. Essa habitação é denominada de onírica, pois nela o ser humano pode se entregar ao devaneio, aos sonhos noturnos e diurnos, ao sono da fantasia. Com os devaneios, nasce a casa dos sonhos, o templo da casa natal, no qual se condensam todas as lembranças das diversas moradas habitadas e vividas pelo homem, bem como as primeiras experiências de habitar no lar paterno, que ajudam a formar a "imagem primitiva da casa" (BACHELARD, 2008).

A casa de três andares de Bachelard é uma metáfora do ser humano: id, ego e superego. Analogia semelhante foi evocada por Henri Bosco, ao descrever uma casa considerada oniricamente completa, sendo, pois, um "arquétipo sintético" e um dos esquemas verticais da psicologia humana: com o porão representando a caverna, a raiz (o inconsciente) e o sótão, o ninho (funções conscientes) (BACHELARD, 2008).

Nessa relação íntima com seus habitantes, a casa chega à vida e se torna um ser móvel e variável. Nossas impressões da casa amada mudam ao longo do tempo e dos acontecimentos que ela suscita ou acolhe (...). Espelho dos movimentos da alma, ela tem flexibilidade e se recusa a ficar essa construção de pedra imutável e parada (...). Espelho de seus habitantes, ela revela também na sua materialidade a realidade das coisas. Se habitamos, fazemo-los juntos com o mundo inteiro. $\mathrm{Na}$ sua presença ao mundo com o qual temos que conviver, a casa tem uma função sacerdotal de revelação do mistério do universo (BACHELARD, 2008). 
Discorrendo sobre o conceito de habitar, Heidegger (1986) afirma que o seu significado fundamental é o de ser um determinado ponto, estar enraizado nele, estar em casa. Também significa ter um âmbito fechado, acolhedor, um espaço próprio, no qual o homem se retira e se abriga do mundo exterior, ameaçador e hostil. Nesta acepção, o habitar opõe-se a uma estada casual, meramente passageira ou temporária, num determinado ponto arbitrário do espaço, ou seja, o significado fundamental é o "habitar uma casa".

Se as filosofias da existência encaravam o homem como um ser lançado num mundo arbitrário, contingente, não escolhido e absolutamente estranho, as filosofias do habitar consideram que a essência do homem é totalmente determinada a partir do habitar. Como afirma Bachelard (2008), o homem habita a sua casa antes de habitar o mundo. Para o filósofo, a casa é educativa: ela é paterna, é o berço da educação. Isto quer dizer que a casa, além de dispensar interiormente calor, comodidade, repouso, tranquilidade, afeto, serenidade e acolhimento, dá ao homem, na sua relação com o mundo exterior, firmeza e força para prevalecer contra o mundo. A casa ajuda a dizer: serei um habitante do mundo, a despeito do mundo.

\section{Contemporaneidade: que casas? quais casas? para quêe? para quem?}

Entretanto, cada vez mais, a casa tem sido, na sociedade contemporânea, para além de resposta objetiva e funcional, um sinal de status. No início do século XX, Charles Edouard Jeanneret-Gris, mais conhecido pelo pseudônimo de Le Corbusier, diante da era mecânica e mecanicista, designou a casa como "máquina para habitar", tendo obtido rápida adesão, pois, em suas palavras: "se a expressão fez sucesso, é porque ela contém o termo 'máquina', representando, com evidência, em todos os espíritos, a noção de funcionalismo, de rendimento, de trabalho e produção", fundamental para o Sistema Capitalista. 
Le Corbusier (1986) vai estabelecer cinco pontos sobre os quais devem-se levar em consideração a construção da "casa máquina para habitar", quais sejam: a planta livre, que através de uma estrutura independente permite a livre locação das paredes, já que estas não mais precisam exercer a função estrutural; a fachada livre, resultante igualmente da independência da estrutura. Assim, a fachada pode ser projetada sem impedimentos; os pilotis, um sistema de pilares que elevam o prédio do chão, permitindo o trânsito por debaixo do mesmo; o terrraço jardim, para "recuperar" o solo ocupado pelo prédio, "transferindo-o" para cima do prédio na forma de um jardim; e as janelas em banda que, possibilitadas pela fachada livre, visam a permitir uma relação desimpedida com a paisagem.

O sucesso dos cinco pontos foi tal que, com o tempo, estes deixaram de ser associados apenas a Le Corbusier e se tornaram cânones da arquitetura moderna. Assim, arquitetos de países diversos adotaram os preceitos, parcial ou integralmente, em suas construções, como por exemplo, no Brasil, os projetos de Lúcio Costa e Oscar Niemeyer, entre outros, (com a consultoria de Le Corbusier), utilizando integralmente os cinco pontos arquitetônicos.

Atualmente, para além de todas as "funções” que a casa ocupa, é um dos "centros" de uma grave crise financeira internacional, provocada pela especulação imobiliária irracional, carente de visão do passado glorioso e do futuro aberto ao novo, flutuante nas bolhas das bolsas de valores, que estouraram e explodiram seus gases por todo o mundo.

Entretanto, ainda permanece a vinculação de casa com o conceito de habitar, mas ressalta-se que há muitas situações (mais do que as desejáveis), em que a rua é mais segura do que uma casa.

Há, quase (?) invisíveis para a população circundante, as centenas, milhares, milhões (?) de pessoas que se arrastam durante o dia, como zumbis, carregando seus pertences, os quais, muitas vezes, são desprezados, seja pela inutilidade para a ocasião (como mudança de 
estação, por exemplo, quando cobertores e agasalhos são abandonados ao léu), seja pela dificuldade de, além de arrastar-se, arrastar consigo sua... vida, casa (?), sua provisoriedade. Estes "vivem" e dormem em formas multifacetadas, improvisadas com papelão sob os viadutos, nas praças, nas calçadas, nos degraus, terraços e varandas de prédios públicos, envolvidos pelos mantos da caridade alheia, produtos de roubos e furtos ou rasgos de tecidos e plásticos de um passado que muitos nem lembram mais.

Se o modernismo preocupava-se com o novo, tentando-se captar sua essência, o pós-modernismo busca as rupturas.

Nesse contexto pós-moderno, podem ser observadas essas mudanças, que são de toda ordem e estão em todos os lugares. Mas, como não é possível tratar delas de modo tão amplo, pode-se tomar como objeto de análise aquilo que se chama de microcélula da sociedade, a família. Fazendo o caminho do particular para o geral, a observação da reconfiguração que sofreu a família nas últimas décadas pode ser ilustrativa de algumas das transformações operadas no "mundo pós-moderno" (...) se uma das características da lógica pós-moderna é a desconstrução, parece mesmo que a família é o exemplo mais contundente desse processo (...) as mudanças econômicas, operadas em âmbito mundial, também atuaram sobre a estrutura familiar, que não é apenas aquela instituição fundada no matrimônio, patriarcal e heterossexual. Quanto ao matrimônio, sabe-se que no mundo pós-moderno, família não é mais sinônimo de casamento, instituição civil e religiosa que representava o núcleo indissolúvel. Agora se refere à junção de sujeitos sociais que compartilham alguns interesses em comum (PACHECO, TRISOTTO, 2006). 
Quando a família, estrutura sobre a qual se alicerçaram os grupos sociais, sofre grande transformação, o seu lócus - a casa - também muda, e não só de formato ou estrutura, mas de status. Pois, antes a casa era elo de ligação dos familiares e símbolo sagrado da família, espaço de reuniões, comemoração de casamentos e aniversários, ponto de partida dos mortos, símbolo dos laços consanguíneos e dos valores sociais, extensão da família, sinônimo de coletivo, de reunião e de troca; agora, configura-se em espaços individuais - "meu quarto, onde eu assisto ao programa que eu quero, na minha televisão ou no meu escritório, onde leio os meus e-mails" (PACHECO, TRISOTTO, 2006). Cada morador usa os espaços onde e quando quer, a seu tempo, e até as refeições são feitas nos mais diversos lugares e horários.

Também não há mais necessidade ou condição, para que se more em uma "casa", esta função pode ser desempenhada por um apartamento - forma mais valorizada - um hotel, flats, barcos, barracas de acampamentos ou barracos, talvez os mais numerosos, resultante das iniquidades sociais. Aqui, voltamos aos princípios vitruvianos e albertinianos fundamentados em valores, ali, oligárquicos:

Talvez esta evidência seja suficiente para demonstrar que alguns edifícios são apropriados para a sociedade como um todo; outros para os primeiros cidadãos [classe de maior poder aquisitivo], e ainda outros para as pessoas comuns [menor poder aquisitivo]. Novamente, entre os primeiros cidadãos, aqueles presidindo conselhos domésticos requerem edifícios diferentes daqueles para os envolvidos na execução de decisões ou aqueles engajados no acúmulo de riquezas (ALBERTI, 2002).

Aqui abrimos um pequeno parêntese para registrar outra forma de moradia: as favelas - uma "modalidade" urbanística própria do Brasil, em função, na maioria dos casos, da geopolítica e da 
concentração de renda, uma das maiores do planeta. Ali se encontram tantos tipos de moradias estruturadas em um emaranhado que tem chamado a atenção de grupos internacionais envolvidos com questões arquitetônicas e políticas públicas. Entretanto, seriam necessários inúmeros estudos para dar conta de todas as dobras de tal cenário no contexto brasileiro.

Portanto, hoje, para os que não se encaixam como detentores do poder ou acumuladores de riqueza, restam outras formas de casa, cuja construção ou montagem não segue nenhum tratado, ideal ou de preocupação urbanística, mas se definem pela posição ocupada (ou nenhuma) na sociedade pós-moderna, imprimindo uma nova trama na paisagem das cidades.

\section{Os direitos ainda não estão nas leis, as leis ainda não estão efetivadas, a questão não é meramente jurídica}

Diante do real experienciado, construído, destruído, reconstruído, reaproveitado e reciclado, emergiu a necessidade de assegurar-se, pelo menos em dispositivos jurídico-legais, a habitação como direito fundamental.

Que já estava previsto na Declaração dos Direitos Humanos, de 1948. Pela sua relevância e influência, é destaque em documentos oriundos de duas grandes conferências, no plano internacional, promovidas pela Organização das Nações Unidas (ONU). A primeira, realizada em 1976, sobre a problemática dos assentamentos (Declaração de Vancouver sobre Assentamentos Humanos - Habitat I), que reafirma o reconhecimento do direito à moradia como fundamental e de realização progressiva, com remissão expressa aos pactos internacionais anteriores; a segunda, de 1996, com sede em Istambul - Turquia, resultou na Agenda Habitat II, tida como o mais completo documento na matéria, do qual também o Brasil é signatário, onde, além do reafirmamento do direito, consta uma minuciosa 
previsão quanto ao conteúdo e extensão do direito à moradia, bem como das responsabilidades gerais e específicas dos Estados signatários para a sua realização, que voltarão a ser objeto de referência. Atualmente, mais de cinquenta Constituições reconhecem expressamente um direito fundamental à moradia.

Para além disso, sempre haveria como reconhecer um direito fundamental à moradia como decorrência do princípio da dignidade da pessoa humana (art. $1^{\circ}$, inciso III, da Constituição Federal), já que este reclama, na sua dimensão positiva, a satisfação das necessidades existenciais básicas para uma vida com dignidade, podendo servir até mesmo como fundamento direto e autônomo para o reconhecimento de direitos fundamentais não expressamente positivados, mas inequivocamente destinados à proteção da dignidade (LEVY, 2008).

No Brasil, a Constituição, no texto original, trazia, no Art. $6^{\circ}$, a seguinte redação: "são direitos sociais a educação, a saúde, o trabalho, o lazer, a segurança, a previdência social, a proteção à maternidade e à infância, a assistência aos desamparados, na forma desta Constituição". Entretanto, só com a aprovação da Emenda Constitucional 26/2000, o texto passou a vigorar da seguinte forma: "são direitos sociais a educação, a saúde, o trabalho, a moradia, o lazer, a segurança, a previdência social, a proteção à maternidade e à infância, a assistência aos desamparados, na forma desta Constituição”.

Pode, eventualmente, passar despercebida ou ser encarada como um mero detalhe a inclusão do termo moradia, neste artigo. Entretanto, foi a partir de todo um debate e muitas discussões ocorridas na Câmara dos Deputados que foi possível tal inserção. Os movimentos sociais realizaram forte pressão para que, posteriormente, fosse aprovado o Estatuto da Cidade, onde foram disparados instrumentos para o início da Reforma Urbana no país. 
Tal documento trouxe a possibilidade legal que existe atualmente de se desapropriar terrenos que não são usados para moradia e prestam-se à especulação imobiliária, além do lançamento de programas de governo para auxílio à moradia, Leis e outros instrumentos que desencadeiam significativas mudanças.

Se a questão extrapola o âmbito jurídico, faz-se necessário apontar algumas características básicas do que seja uma moradia: atender ao mínimo existencial e à dignidade da pessoa humana, sendo exequível (operacional e financeiramente) para os gestores das políticas habitacionais, pois "o direito de moradia considerado em sua dupla fundamentalidade (formal e material) é eminentemente prestacional (positivo), ou seja, reclama, ab initio, a realização de políticas públicas para a sua outorga efetiva" (LEVY, 2008). E ainda: "segurança jurídica da posse, disponibilidade de serviços e infra-estrutura, custos da moradia acessível, habitabilidade, acessibilidade e localização e adequação cultural" (SAULE JÚNIOR, 2004).

$\mathrm{O}$ direito de moradia encontra-se na base da maioria dos demais direitos fundamentais sociais assegurados pela Constituição Federal. Em outras palavras, pode-se dizer (sem risco de analogias eventualmente positivistas) que se trata da base material, física, a partir da qual vários outros direitos fundamentais podem ser exigidos utilmente pelos cidadãos (...). Partindo da afirmação de que a moradia é direito fundamental que empresta substrato físico à maioria dos direitos fundamentais sociais assegurados pela Constituição Federal, na medida em que constitui a base material a partir da qual vários outros direitos fundamentais podem ser exigidos utilmente pelos cidadãos, sendo de central importância para a ordem jurídico-urbanística a delimitação do conceito de moradia (BOHERER, CABISTANI, 2009). 
Mas, embora a Constituição Federal tenha explicitado o direito à moradia como fundamental, não lhe conferiu um conceito ou extensão precisos:

A devida compreensão do conceito de moradia é indispensável no sentido de afirmar "qual é a moradia" que atende aos desígnios do mínimo existencial. (...) A complexidade do conceito encetado inicia-se nas questões referentes à disponibilidade de recursos públicos e termina nas dificuldades impostas pela burocracia registral, passando pelos problemas decorrentes do caráter multidisciplinar da matéria e de seu inegável cunho político, sendo desnecessário referir que essa complexidade cresce na medida em que cresce o déficit habitacional das cidades. A conceituação de moradia indigna pode ser facilmente extraída dos elementos insertos nos dados do déficit habitacional qualitativo. Contudo, seu conceito inverso é bem mais tormentoso e exige um esforço interpretativo e conseqüente que leve em consideração os elementos jurídicos, sociais, culturais e financeiros ínsitos na ordem urbanística, vez que não basta à conflagrada realidade habitacional do país um conceito meramente jurídico de moradia (LEVY, 2008).

Tomando como ponto de vista o dos movimentos societários pela reforma urbana, o Estatuto da Cidade representa um importante marco no reconhecimento da importância das contradições e conflitos da problemática urbana, o que significa reconhecer a cidade real e não apenas a cidade ideal e/ou a legal. Trata-se, portanto, de um longo processo de reconhecimento de que a cidade é produzida coletivamente e que sua gestão deve ser democrática. 
A seguir, são apresentados alguns aspectos do Estatuto da Cidade e a criação de mecanismos e instrumentos que visam a torná-lo efetivo (BRASIL, 2001a):

I - A participação da sociedade como elemento fundamental para a elaboração da Política Urbana;

II - É dever do Estado assegurar o direito de morar a quem não dispõe de moradia digna, obrigando-o a conceder este direito em imóvel privado com delimitação de áreas especiais para moradia, reconhecimento do usucapião e regularização fundiária nas áreas ocupadas, parcelamento e a edificação compulsória, IPTU progressivo no tempo, operações urbanas consorciadas, transferência do direito de construir, direito de perempção.

III - O reconhecimento dos sujeitos coletivos da produção e do consumo da Cidade (...). Assim os que não eram reconhecidos como produtores da cidade, mas apenas como geradores de problemas urbanos passam a ser vistos como sujeitos coletivos da produção e do consumo e a cidade passa a ser compreendida como espaço coletivo. Os problemas deixam de ser analisados como desvios do modelo e podem ser enfrentados como decorrentes de própria dinâmica da urbanização.

Porém, o Estatuto da Cidade não resolve todos os conflitos, até pelo contrário, permite que deixem de ser ocultos, possibilitando aos diversos atores, agentes, sujeitos que explicitem suas diferenças para que a cidade, uma produção coletiva, tenha uma função social no interesse da maioria (RODRIGUES, 2009). 
De acordo com dados do Ministério das Cidades, o déficit habitacional estimado, em 2006, era de 7,935 milhões de domicílios, a maioria em áreas urbanas: 6,543 milhões. Observa-se, a partir da Pesquisa Nacional por Amostra de Domicílios (PNAD) de 2006, que uma das tendências que se consolida é a confirmação da região Sudeste como responsável pelo maior número das carências habitacionais, papel anteriormente desempenhado pela região Nordeste. Outro grave problema são os domicílios inadequados (estimados em 11, 247 milhões), que representam $24,1 \%$ das moradias urbanas.

Como inadequados são classificados os domicílios com carência de infraestrutura, com adensamento excessivo de moradores, com problemas de natureza fundiária, em alto grau de depreciação ou sem unidade sanitária domiciliar exclusiva. $\mathrm{O}$ maior fator de inadequação é a carência de infraestrutura, caracterizada pela ausência de atendimento adequado em um ou mais serviços básicos, como iluminação elétrica, rede geral de abastecimento de água, rede geral de esgotamento sanitário ou fossa séptica e coleta de lixo. Percentualmente o problema se torna mais relevante nas regiões Norte, Centro-Oeste e Nordeste, presente em mais de $40 \%$ dos seus domicílios urbanos. Acrescentam-se, ainda, a essa contabilidade, os domicílios em situação de déficit habitacional localizados em aglomerados subnormais (BRASIL, 1998).

A questão do uso do solo para a efetividade da moradia tem suscitado guerras, conflitos e disputas, o que tem demandado a implantação ou elaboração de instrumentos para dirimir dúvidas legais e garantir direitos. Surge, como enfrentamento a essa questão, entre tantos outros, o denominado bem de família. Este instituto jurídico tem sua gênese nos Estados Unidos da América, no estado do Texas, através da edição da Lei do Homestead, em 26 de janeiro de 1839. O significado da expressão Homestead reporta-se ao local do lar (home=lar; setead=local), surgida em defesa da pequena propriedade e que objetivava proteger as famílias radicadas naquela região. 
O Homestead surge em defesa da pequena propriedade, e traduzido ao português significa local do lar. O sentimento herdado da nação inglesa, de considerar a casa um castelo sagrado e de oferecer proteção ao colono ou imigrante, é a razão de existência do instituto do Homestead. A casa era um castelo protegido e sagrado em menor proporção: era o colono ou imigrante que mantinham tais castelos e, deviam ser protegidos para a própria manutenção destes. A Constituição Texana de 1836, antes da Lei do Homestead, tratava das linhas gerais do instituto, possibilitando a todo cidadão do Texas, com exceção dos negros africanos e de seus descendentes, a obtenção junto ao Governo de uma pequena porção de terras do Estado, desde que fosse chefe de família: "de agora e após esse ato, deverá ser reservado a todo cidadão ou chefe de família, nesta república, livre e independentemente do poder da escritura de fieri facias, ou outra execução, emitindo de qualquer corte de qualquer jurisdição competente, cinquenta acres de terra, ou um lote urbano incluso como local do lar dele ou dela, e suas melhorias" (AZEVEDO, 2002).

Diante disso, o bem de família é um meio de proteção familiar, garantindo-lhe um teto, uma casa de morar imune às futuras execuções, salvo exceções legais, definidas caso a caso nos ritos processuais. Ou seja, o bem de família é o nome dado ao imóvel de um casal, ou de uma entidade familiar, que, por proteção legal, não pode ser penhorado. Tal garantia pode ser instituída voluntariamente pelos cônjuges ou entidade familiar, por meio de escritura pública devidamente registrada no Registro de Imóveis, observadas as formalidades legais. 
Este dispositivo já estava previsto no Código Civil de 1916 (Lei $n^{\circ} 3.071$, arts. 70 a 73). Em 1990, foi editada a Lei 8.009/90, que em seu Art. $1^{\circ}$ dispõe: "O imóvel residencial próprio do casal, ou da entidade familiar, é impenhorável e não responderá por qualquer tipo de dívida civil, comercial, fiscal, previdenciária ou de outra natureza, contraída pelos cônjuges ou pelos pais ou filhos que sejam seus proprietários e nele residam, salvo nas hipóteses previstas nesta Lei" (BRASIL, 1990). Com a promulgação desta Lei, o instituto difundiu-se largamente, uma vez que o bem de família passou a ser legal, ou seja, "prescindindo da interveniência do proprietário do imóvel, posto que ditado pelo Estado, que passou a excluir da penhora o imóvel residencial de qualquer brasileiro, rico ou pobre, em face de execuções de qualquer espécie, salvo algumas poucas exceções" (VALLIATI, 2007).

Portanto, o bem de família é declarado inalienável pelo art. 72, do código Civil. A inalienabilidade vem estabelecida pela Lei com o propósito de salvaguardar a família do instituidor, proporcionando-lhe seguro asilo. Se os interessados ou donos do imóvel forem incapazes, o consentimento deve ser dado pelos representantes legais, por meio da nomeação de um curador especial, nos termos do art. 387, do Código Civil, se for o caso. É perante o juiz da cidade em que residem os interessados em bem de família que se deve promover seu cancelamento. Entre os interessados se acham os filhos do instituidor, que têm qualidade para se opor ao cancelamento (BRASIL, 2002).

O que vem sendo dito até o momento, tem a função de ampliar as concepções sobre a importância da moradia e do habitar para o ser humano, pois é um fato imbricado em todas as suas relações socioeconômica-culturais. 


\section{Residências Terapêuticas: emergências e contradições na territorialização da loucura no país - ainda uma alienação}

Cabe, a partir desse ponto, discorrer sobre a pretensão(?) de se pensar em moradias para os sofredores psíquicos, para isso, faremos uma viagem nos caminhos e descaminhos percorridos pela loucura, para que possamos desnaturalizar as concepções e refletir acerca das práticas que são realizadas atualmente na assistência às pessoas em sofrimento mental.

Tal ideia pauta-se na revelação de que tanto a loucura quanto os modos de responder a ela emergem de determinados contextos sociais, ou seja, a loucura é um fenômeno social e possui as marcas da sociedade em que fora criada, sendo pensada como bênção divina (Antiga Grécia), possessão demoníaca (Idade Média), até ser apreendida, no final do Século XVIII, como objeto da psiquiatria, isto é, como doença mental (FOUCAULT, 2004), dando início à época, que ficou conhecida, como período das grandes internações manicômiais, onde os hospitais psiquiátricos e asilos tinham a função de retirar, das ruas, aqueles sujeitos que trouxessem desordem social, ou seja, mendigos, prostitutas, vagabundos e "loucos" que, após serem segregados, eram submetidos a tratamentos desumanos, como eletrochoque, insulinoterapia, lobotomia e torturas, sendo esses ditos para a cura.

Então, o que predominou foi a compreensão da doença mental como o desvio das normas sociais, que quebra os padrões vigentes de comportamento sociável, razão pela qual o sujeito é rotulado como doente "louco", com o enfoque predominante da periculosidade social, da insanidade, da incapacidade para o trabalho, ou seja, os "loucos" eram (são?) considerados um impasse ao desenvolvimento econômico das cidades. 
Com o surgimento às instituições asilares, no período das grandes internações psiquiátricas, a medicina, através da figura do psiquiatra, assume um papel de anti-herói, onde, tendo como pano de fundo o discurso terapêutico, exerce sua principal tarefa: a de controle social-gessado.

Gessado sim, pois, como resultado de sua prática, cria-se o rótulo de doente mental, onde os sujeitos que são batizados com ele, deixam de fazer parte de uma classe social e econômica e assumem, de forma vitalícia, o "título de louco", de modo que, mesmo após anos e anos de tratamento no hospital psiquiátrico, entende-se que não há retorno à normalidade.

Para Pinel, precursor da prática médica psiquiátrica, os manicômios eram locais apropriados para analisar a doença mental, determinou o princípio do isolamento para os alienados e instaurou o primeiro modelo de terapêutica nesta área ao introduzir o tratamento moral, "libertando-os" para que pudessem ser descritos e classificadas suas patologias.

Curioso é observar que Pinel não elege o termo doença mental, mas alienação mental. Que significava um distúrbio no âmbito das paixões, capaz de produzir desarmonia na mente e na possibilidade objetiva do indivíduo perceber a realidade. No sentido mais comum do termo, alienado é alguém "de fora”, estrangeiro, alienígena. "Pode ainda significar estar fora da realidade, fora de si, sem o controle de suas próprias vontades e desejos. Fora do mundo, de outro mundo (no mundo da lua). Alienação, perda da razão, irracionalidade, animalidade" (AMARANTE, 2007).

Esse conceito de alienação mental nasce associado à ideia de periculosidade, contribuindo para produzir, como condição inerente a própria noção, uma atitude social de medo e discriminação para com os sujeitos identificados como tais.

Ao perceber a doença mental a partir da classificação de Pinel, como destituída de razão, o indivíduo perde o seu direito do livre- 
arbítrio e, consequentemente, da liberdade conferida pela própria Declaração dos Direitos Humanos, pela Revolução Francesa e pela base do Estado de Direito, o qual afirma que "todos têm direitos iguais perante a constituição". Desse modo, se o indivíduo não é livre, consequentemente não é cidadão (AMARANTE, 1995); além de que, para complementar, é considerado um irresponsável civil.

Nesse processo, o doente é distanciado do seu ambiente de vivência cotidiana, rompendo com os laços sociais e familiares, que poderiam ajudá-lo a se reintegrar, iniciando a chamada "carreira moral do doente mental" que culmina, na maioria das vezes, na cronificação do seu transtorno. O lugar do doente agora é uma cela hermética, na qual uma vez trancafiado, nunca mais pode sair. Simbolicamente, esta cela sempre estará ao seu redor, pois a doença mental, como identidade social, não mais permite ao ex-interno de um manicômio o retorno à comunidade como se nada houvesse ocorrido - ele sempre será o 'louco'?

Se por um lado, o surgimento da psiquiatria propõe uma finalidade terapêutica, por outro, cumpre uma função de normatização do espaço social mediante os dispositivos psiquiátricos tradicionais (hospitais psiquiátricos), ou dos modernos psicofármacos, que permitem uma outra forma de controle social das pessoas que desviam da norma, portanto, o foco central do tratamento psiquiátrico convencional é o controle social por meio do sistema hospitalocêntrico (DALMOLIN, 2006).

"Sem este asilo (...) nada poderia fazer, ele dá-me, porém, muito maior campo aos meus estudos" (ASSIS, 1995). Poder-se-ia pensar ser esta uma declaração emitida por Pinel, contudo, provém do personagem principal de um dos clássicos de Machado de Assis - "O Alienista” - publicado entre 1881 e 1882, e que trata de uma narrativa entremeada na vida do fictício médico Simão Bacamarte.

Machado é pioneiro na crítica ao saber psiquiátrico e aos manicômios no Brasil, como expresso na fala do personagem principal que, 
recém-chegado da Europa, decide, a partir de uma exigência externa e artificial, fundar um hospício para internar os loucos de sua cidade, por não lhes ser fornecida a devida atenção (ASSIS, 1995).

Na obra, o autor mostra a criação da Casa Verde pelo alienista, onde lhe seria possível juntar todos os loucos em um só local, e dedicar-se ao estudo da loucura, na tentativa de entender seu significado. Paulatinamente, vai fundamentando uma crítica à ciência como verdade inquestionável, sobre o que é o normal e a função do alienismo (futuramente a psiquiatria) como necessária à ordem pública. Chama a atenção o fato de Machado denominar o asilo de "casa" e, ainda por cima, qualificá-la com uma cor verde, indo de encontro ao que Erving Goffman (2003), posteriormente, denominou de instituições totais, caracterizadas como frias, impessoais, cuja arquitetura se reproduz em manicômios, prisões e conventos, marcados com cores neutras, impregnadas de mensagens cifradas, tintas produzidas a partir de fluidos e outras invenções de seus habitantes. Interessante, também, é perceber as semelhanças entre esse clássico da literatura nacional, com a história de Phelippe Pinel, diretor dos hospitais psiquiátricos de Bicetre e Salpêtriere, e seu trabalho no processo de construção do alienismo.

Contudo, a eficácia desse modelo hospitalocêntrico e médico/ psiquiátrico centrado começou a ser questionado efetivamente, por volta dos anos 60. As críticas apontavam para uma crise do sistema psiquiátrico, que além de não intervir na qualidade de saúde dos internos, era, segundo seus críticos, o produtor e mantenedor do adoecimento, responsável pelo alto índice de mortalidade e cronificação dessas pessoas, gerando inúmeras incapacidades sociais.

Diante deste processo, surge a figura do italiano Franco Basaglia (1991) que considerava o hospital psiquiátrico/manicômio uma experiência opressiva e trágica, um espaço rígido onde todas, ou quase todas, as dimensões da vida eram controladas por uma autoridade e, portanto, precisavam ser confrontadas entre os componentes da comunidade no cotidiano. Em decorrência dos seus pensamentos, 
cria-se o movimento de reforma psiquiátrica italiana ou "psiquiatria democrática italiana", um exemplo de sucesso a ser seguido na luta contra a reversão da assistência psiquiátrica hospitalar.

O Brasil, em particular, orientou sua reforma psiquiátrica inspirando-se na experiência italiana, de reversão dos hospitais psiquiátricos por dispositivos inseridos e articulados socialmente, com o intuito de alcançar a reinserção socioeconômica-cultural das pessoas em sofrimento mental e de re-estruturar as práticas de cuidados despendidas a essas.

O início legal da reforma, no Brasil, ocorreu com a apresentação do Projeto de Lei 3.657/89, o qual propunha a regulamentação dos direitos da pessoa com transtornos mentais e a progressiva substituição dos manicômios no país. Entretanto, foi somente depois de doze anos de tramitação pelo Congresso, que veio a aprovação, sendo transformado na Lei 10.216, em 6 de abril de 2001, a qual ficou conhecida como Lei da Reforma Psiquiátrica ou ainda Lei Paulo Delgado. Esta garante o processo de substituição progressiva dos leitos em hospitais psiquiátricos por uma rede comunitária de atenção psicossocial (BRASIL, 2001a).

Um dos maiores méritos dessa Lei é a explícita definição dos direitos da pessoa com transtornos mentais, devendo ser tratada com humildade e respeito e no interesse exclusivo de beneficiar sua saúde, visando a alcançar sua recuperação pela inserção na família, no trabalho e na comunidade; ser protegida contra qualquer forma de exploração; [...] ser tratada em ambiente terapêutico pelos meios menos invasivos possíveis; ser tratada preferencialmente, em serviços comunitários de saúde (BRASIL, 2001b). Logo, segundo o Ministério da Saúde, o momento atual de reforma psiquiátrica, no Brasil, é identificado por dois movimentos simultâneos e paralelos: a criação e a implantação de uma rede de atenção à saúde mental substitutiva e a monitorização e a redução progressiva e programada de leitos psiquiátricos existentes (BRASIL, 2005). 
Nesse contexto, a desinstitucionalização reordena as ações no campo da saúde mental a outro objeto, que é o sofredor psíquico, e não à doença. Para a execução da Reforma Psiquiátrica, edificar-se e efetivar-se na prática da não-exclusão, nos caminhos da desinstitucionalização, é preciso reconhecer o doente mental como sujeito de direitos e deveres, pressupondo mudanças culturais e subjetivas na sociedade, quebrado a visão dogmática em relação à loucura (AREJANO; PADILHA; ALBUQUERQUE, 2003).

Na luta para reversão desse panorama de atenção psiquiátrica hospitalocêntrica, a política de saúde vem se dedicando, nos últimos anos, para conseguir a efetiva desinstitucionalização e a reinserção dos sofredores psíquicos na sociedade. Para isso, tem contado com apoio integral dos serviços substitutivos, em especial, com as Residências Terapêuticas, espaço de morar e viver na comunidade, para egressos de internações manicomiais de longos períodos.

As Residências Terapêuticas ou moradias possuem a função de reduzir leitos dos hospitais psiquiátricos e superar a condição cronificante de "moradores do hospital", a que muitas pessoas foram relegadas, pois implica em alternativas de moradias para os egressos da instituição psiquiátrica, seja pelo suporte requerido para garantir sua permanência fora dela, seja pela dificuldade de reinserção familiar.

Para reforçar a ideia de que a Residência Terapêutica tem o propósito de ser a "casa" para os egressos de manicômios, a Portaria 106/2000 (BRASIL, 2004a) estabelece, no Art. $6^{\circ}$ :

Art. $6^{\circ}$ Definir que são características físico-funcionais dos Serviços Residenciais Terapêuticos em Saúde Mental:

6.1 apresentar estrutura física situada fora dos limites de unidades hospitalares gerais ou 
especializadas seguindo critérios estabelecidos pelos gestores municipais e estaduais;

6.2 existência de espaço físico que contemple de maneira mínima:

6.2.1 dimensões específicas compatíveis para abrigar um número de no máximo 08 (oito) usuários, acomodados na proporção de até 03 (três) por dormitório.

6.2.2 sala de estar com mobiliário adequado para o conforto e a boa comodidade dos usuários;

6.2.3 dormitórios devidamente equipados com cama e armário;

6.2.4 copa e cozinha para a execução das atividades domésticas com os equipamentos necessários (geladeira, fogão, filtros, armários, etc.);

6.2.5 garantia de, no mínimo, três refeições diárias, café da manhã, almoço e jantar. (BRASIL, 2004).

Porém, a admissão de um usuário na residência é o começo de um longo processo de reabilitação que deverá buscar a progressiva inclusão social do morador e sua emancipação pessoal, afinal, sua finalidade principal é a moradia, o morar e o viver na cidade (BRASIL, 2004b). E isso, a experiência tem demonstrado que não é "missão" tão simples, como a legislação enseja acontecer ou quando idealizada: "a casa é uma parte inalienável de seus moradores, ela tem a presença e a força de um membro, a sua força é, às vezes, mais poderosa que as ligações familiares que ela pode substituir" (A CASA..., 2008). 
Como relata Abitbol (1966) (referindo-se a acontecimentos importantes decorrentes de um conjunto de leis promulgadas em 1964, na Costa do Marfim, e que visavam a estabelecer códigos para a solidariedade familiar e proteção à orfandade):

As reformas não serão sem riscos. É difícil regulamentar através de leis as relações familiares, sobretudo quando isso significa uma grande mudança das instituições preexistentes. A oposição que pode provocar a intromissão do Estado em um domínio que lhe escapa totalmente, é impossível de prever as reações sociais que suscitará o novo sistema e as desordens que ele pode engendrar. (ABITBOL, 1966) [Grifos da autora].

Embora a residência seja entendida, via de regra, como sinônimo de casa, quando se refere a espaços constituídos pelo poder público ou outras instituições, tal termo designa um espaço de moradia para grupos, como exemplo, as residências universitárias. Assim, contextualizando para o cenário paraibano, já se percebe certa inadequação do termo "residência", pois na região, denomina-se o local de moradia como "casa". Outras inadequações podem ocorrer, particularmente quando a Reforma Psiquiátrica e o processo de desinstitucionalização, embora regulamentados, são implantados em um país com dimensões continentais e realidades geográficas, econômicas, culturais, religiosas, educacionais, entre tantas, produzem e reproduzem universos e experiências diversas e, por vezes, díspares.

Mas um ponto central a se destacar agora, diz respeito à condição do/a morador/a, quanto à inalienabilidade de seu novo lar. Do ponto de vista legal, a casa não é deles, uma vez que a Secretaria Municipal de Saúde loca o imóvel. Tal fato pode ocasionar o deslocamento e reterritorialização destes sujeitos, caso vença o contrato de locação e/ou o proprietário solicite o imóvel, motivado por, 
entre outros motivos, denúncias ou movimentos de interdição da Residência Terapêutica por parte da vizinhança.

Se o portador de transtorno psíquico não se enxerga na casa como dono ou proprietário, continua "alienado". O conceito de alienação é comum a vários domínios do saber:

...a condição psico-sociológica de perda da identidade individual ou coletiva decorrente de uma situação global de falta de autonomia. Encerra, portanto, uma dimensão objetiva - a realidade alienante - e a uma dimensão subjetiva - o sentimento do sujeito privado de algo que lhe é próprio (...). Em antropologia, a alienação é o estado de um povo forçado a abandonar seus valores culturais para assumir os do colonizador. Em sociologia e comunicação, discute-se a alienação que a publicidade e os meios de comunicação suscitam, dirigindo a vontade das massas, criando necessidades de consumo artificiais e desviando o interesse das pessoas para atividades passivas e não participativas. Em filosofia política, fala-se de alienação para designar a condição do trabalhador que, à semelhança de uma peça de engrenagem, integra a estrutura de uma unidade de produção sem ter nenhum poder de decisão sobre sua própria atividade nem direitos sobre o que produz (AZEVEDO, 2002).

Conjugando tais conceituações com a definição utilizada em psicologia e psiquiatria - "fala-se de alienação para designar o estado mental da pessoa cuja ligação com o mundo circundante está enfraquecida" (ALIENAÇÃO..., 2007) - podemos deduzir, então, que o sujeito em sofrimento psíquico, agora não mais o louco ou alienado, para efeito de sua inserção no novo modelo assistencial em saúde mental, continua "alienado", no que se refere à posse da casa. Como 
o passado não é algo estático e que não ficou tão-somente para traz, o imaginário social ainda o classifica como alienado e tais sujeitos o continuam a ser, no que se refere a sua moradia, pois que determinada, agora, pelos aspectos mercantil ou econômico-financeiro.

As consequências dessa “alienação” poderão se dar de várias formas e algumas são expressas em relatos do tipo: "essa não é a minha casa". Aqui, podendo-se vislumbrar a sua consciência quanto à propriedade que agora habita e/ou quanto ao seu desejo de voltar para uma casa (lar?) de onde se retirou, fugiu, foi excluído ou expulso e para onde não pode mais voltar, seja porque seus familiares não o querem ou não tenham condições de arcar com o seu cuidado, seja porque o seu adoecimento mental tem estreita relação com a convivência naquela moradia.

\section{Para onde vamos? Ainda, às perguntas... sempre!}

Tais constatações podem servir de subsídios para debates, discussões e enfrentamento de situações de crise decorrentes da mudança para uma Residência Terapêutica, bem como para a elaboração de estratégias que tragam nortes para as experiências singulares dos sujeitos neste processo. A possibilidade de fuga, de volta às ruas, retorno para uma família desestruturada e desestruturante ou para instituições psiquiátricas clássica não pode ser descartada. Uma outra questão diz respeito à constante reflexão se o processo de desinstitucionalização e o arranjo de moradia para egressos proposto pela Reforma corresponde ao real de que necessitam os sujeitos em sofrimento psíquico.

Pois, há relatos que demonstram a dinâmica relacional dos moradores na residência semelhante a uma estrutura de família, onde se encontram presentes relações de afeto, de cuidado um com outro, de proteção e até de conflito, apropriando-se da casa como sendo um espaço deles, mostrando-se "verdadeiros" donos do lar. 
Talvez, tenhamos que perguntar de novo, com Bachelar:

Através das lembranças de todas as casas em que encontramos abrigo, além de todas as casas em que já desejamos morar, podemos isolar uma essência íntima e concreta que seja uma justificativa para o valor singular que atribuímos a todas as nossas imagens de intimidade protegida? (Bachelar, 2008).

\section{Referências}

ABITBOL, E. La famille conjugale et le droit nouveau du mariage en Côte d'Ivoire. Journal of African Law, London, v. 10, n. 3, p. 141-163, 1966.

ALBERTI, L. B. De re aedificatoria. In: VITRUVIUS, P. (Org.). The ten books on architecture. New York: Dover Publications: 2002. p. 37-46.

ALIENAÇÃO. [S.l.:s.n.], 2007. Disponível em: <www.estudantedefilosofia.com.br/ conceitos/alienacao.php >. Acesso em: 15 mai. 2009.

AMARANTE, P. Saúde mental e atenção psicossocial. Rio de Janeiro: Fiocruz, 2007.

AMARANTE, P. Novos sujeitos, novos direitos: O Debate em Torno da Reforma Psiquiátrica. Cad. Saúde Públ. São Paulo, v. 11, n. 3, p. 414-94, 1995.

AREJANO, C. B.; PADILHA, M. I. C. S.; ALBUQUERQUE, G. L.

Reforma Psiquiátrica: uma analítica das relações de poder nos serviços de atenção à saúde mental. Rev. Bras. Enferm., v. 5, n. 56, p. 549-54, 2003. 
ASSIS, M. O alienista e outros contos. São Paulo: Moderna, 1995.

AZEVEDO, Á. V. Bem de Família: comentários à Lei 8.009/90. 5a. ed. São Paulo: Revista dos Tribunais, 2002.

BACHELAR, G. A poética do habitar. São Paulo: Martins Fontes, 2008.

BASAGLIA, F. A Instituição Negada. 2º ed. Rio de Janeiro: Graal; 1991.

BOHERER, C. C. F.; CABISTANI, L. H. Delimitação do conceito de moradia: o atendimento aos desígnios do "mínimo existencial" e a questão dos custos de produção habitacional em Porto Alegre. [S.l.:s.n.], 2009. Disponível em <http://www.anpm.com. br/fotos/artigos/artigo_dra_ Clarissa.doc $>$. Acesso em: 11 maio, 2009.

BRASIL. Lei de n. 10.216, de 06 abr. 2001. Dispõe sobre a proteção e os direitos das pessoas portadoras de transtornos mentais e redireciona o modelo assistencial em saúde mental. Diário Oficial da República Federativa do Brasil, Poder Executivo. Brasília (DF), 9 abr. 2001 a.

. Lei $\mathrm{n}^{\circ} 10.257$, de 10 de julho de 2001. Regulamenta os arts. $182 \mathrm{o}$ e 183o da Constituição Federal, estabelece diretrizes gerais de política urbana e dá outras providências. Diário Oficial da República Federativa do Brasil, Poder Executivo. Brasília (DF), 11 jul. 2001b.

. Lei no 10.406, de 10 de janeiro de 2002. Institui o Código Civil. Diário Oficial da República Federativa do Brasil, Poder Executivo. Brasília (DF), 11 jan. 2002. . Lei no 8.009, de 29 de março de 1990. Dispõe sobre a impenhorabilidade do bem de família. Diário Oficial da República Federativa do Brasil, Poder Executivo. Brasília (DF), 30 abr. 1990. 
. Ministério da Saúde. Legislação em Saúde Mental: 1990-2004. $5^{\circ}$ ed. Brasília: Ministério da Saúde, 2004a.

. Ministério da Saúde. Residências Terapêuticas: o que são, para que servem? Brasília: Ministério da Saúde, 2004b.

Ministério da Saúde. Reforma psiquiátrica e política de saúde mental no Brasil. Documento apresentado à Conferência Regional de Reforma dos Serviços de saúde Mental: 15 anos depois de Caracas. Brasília: OPAS/Ministério da Saúde, 2005.

. Ministério das Cidades. O déficit habitacional brasileiro: um mapeamento por unidades da federação. Rio de Janeiro: IPEA, 1998.

DALMOLIN, B. M. Esperança equilibrista: cartografias de sujeitos em sofrimento psíquico. Rio de Janeiro: Fiocruz, 2006.

FOUCAULT, M. História da loucura. 8a. ed. São Paulo: Edições Graal, 2004.

GOFFMAN, E. Manicômios, prisões e conventos. $7^{\circ}$ ed. São Paulo: Perspectiva, 2003.

HEIDEGGER, M. Batir habiter penser. In: HEIDEGGER, M. (Org.). Essais et conferences. Paris: Gallimard, 1986. p. 278-97.

Le Corbusier. Towards a New Architecture. London: Dover Publications; 1986

LEVY, D. R. Direito fundamental social à moradia digna. [S.l.:

s.n.], 2008. Disponível em: <http://www.aprodab.org.br/eventos/congresso2008/teses/danrlevy01.doc>. Acesso em: 01 jun. 2008. 
PACHECO, E; TRISOTTO, E. A nova casa: arranjos familiares pós-modernos. Uninter, v. 2, n. 20, 2006. Disponível em: <http:// www.grupouninter.com.br/revista/anteriores/index.php@edicao_ $\mathrm{id}=20 \&$ menu_id=4\&id=410>. Acesso em: 12 jan. 2009.

RODRIGUES, A. M. O Estatuto da Cidade: Reforma Urbana e Moradia. [S.l]: Associação brasileira de Geógrafos, 2009. Disponível em: <http:// www.lupa.org.br/ biblioteca/ o\%20estatuto\%20da\%20cidade, $\% 20$ reforma\%20urbana\%20e\%20moradia.pdf>. Acesso em: 23 jul. 2009.

RYKWERT, J. A casa de Adão no Paraíso. São Paulo: Perspectiva, 2003.

SAULE JÚNIOR, N. A Proteção jurídica da moradia nos assentamentos irregulares. Porto Alegre: Fabris, 2004.

SOUSA, F. J. S. Bachelard e Filosofia do Habitar. [S.l.: s.n], 2008.

Disponível em: <http://cyberself-cyberphilosophy.blogspot.com/2008/07/ bachelard-e-filosofia-do-habitar.html>. Acesso em: 20 jun. 2009. 